EXTENDED REPORT

\title{
Interrater reproducibility of clinical tests for rotator cuff lesions
}

\author{
A J K Ostor, C A Richards, A T Prevost, B L Hazleman, C A Speed
}

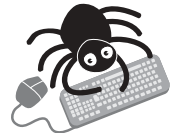

Appendix 1 containing additional tables is available at http://www. annrheumdis.com/ supplemental

See end of article for authors' affiliations

.....................

Correspondence to:

Dr A J K Ostor

Rheumatology Research

Unit, Box 194, Hills Road

Cambridge CB2 2QQ, UK;

andrew.ostor@

addenbrookes.nhs.uk

Accepted 1 December 2003

Background: Rotator cuff lesions are common in the community but reproducibility of tests for shoulder assessment has not been adequately appraised and there is no uniform approach to their use.

Objective: To study interrater reproducibility of standard tests for shoulder evaluation among a rheumatology specialist, rheumatology trainee, and research nurse.

Methods: 136 patients were reviewed over 12 months at a major teaching hospital. The three assessors examined each patient in random order and were unaware of each other's evaluation. Each shoulder was examined in a standard manner by recognised tests for specific lesions and a diagnostic algorithm was used. Between-observer agreement was determined by calculating Cohen's $\kappa$ coefficients (measuring agreement beyond that expected by chance).

Results: Fair to substantial agreement was obtained for the observations of tenderness, painful arc, and external rotation. Tests for supraspinatus and subscapularis also showed at least fair agreement between observers. 40/55 (73\%) $\kappa$ coefficient assessments were rated at $>0.2$, indicating at least fair concordance between observers; $21 / 55(38 \%)$ were rated at $>0.4$, indicating at least moderate concordance between observers.

Conclusion: The reproducibility of certain tests, employed by observers of varying experience, in the assessment of the rotator cuff and general shoulder disease was determined. This has implications for delegation of shoulder assessment to nurse specialists, the development of a simplified evaluation schedule for general practitioners, and uniformity in epidemiological research studies.

$\mathrm{S}$ houlder disorders are common and cause significan morbidity and disability. ${ }^{1-3}$ The annual incidence (episodes for which general practitioners are consulted) of shoulder pain has been estimated to be $>1 \%$ in adults over the age of 45 years, ${ }^{4}$ and the prevalence in population studies lies between 7 and $21 \% .{ }^{5}{ }^{6}$ Lesions of the rotator cuff account for most episodes of shoulder pain (up to $70 \%$ ). ${ }^{6}$ Lack of consensus about appropriate diagnostic criteria for shoulder disorders, however, plagues research in this area. In a review by Buchbinder et al, none of the classification systems for soft tissue disorders of the neck and upper limb appeared acceptable. $^{7}$ This lack of consensus accounts, to a large degree, for the paucity of evidence based management approaches in the treatment of rotator cuff lesions. ${ }^{8}$

The need to develop consensus criteria for upper limb disorders has been recognised by the UK Health and Safety Executive $^{9}$ and has been a major step forward in the development of structured protocols for the evaluation of specific soft tissue disorders. The criteria benefit from consensus backing but have not yet been fully validated. The schedule includes some limited clinical tests of the shoulder. Palmer and colleagues have contributed to the schedule by evaluating the criteria further and by adding items to form the Southampton Examination Schedule for the diagnosis of musculoskeletal disorders of the upper limb. ${ }^{10}$ They found that the schedule was sufficiently reproducible for epidemiological research in the general population. ${ }^{11}$

Despite these steps there is no universally recognised method for evaluating upper limb disorders, with over 20 clinical tests recommended for assessing the rotator cuff alone. ${ }^{12}$ None of these tests have been adequately validated in a general population and their sensitivity and specificity are unknown. As a consequence, patients selected for rotator cuff trials are likely to be a heterogeneous group because inclusion is based on clinical criteria. Further difficulties encountered in shoulder studies are problems with case definition, ${ }^{13}$

variable experience of examiners, ${ }^{14}$ variations in method of assessment, interpretation of physical signs, and diversity of diagnostic categories used..$^{15-19}$ This has contributed to conflicting results in interobserver agreement studies, varying from excellent to poor correlation. ${ }^{20-23}$

To be applicable for widespread use, a test must be accurate and reproducible by clinicians with a spectrum of experience. Our study was undertaken to determine the reproducibility of clinical tests for rotator cuff lesions assessed by clinicians with varying levels of experience. The results would then inform which tests had the closest reproducibility and interrater agreement and, therefore, were the most useful.

\section{METHODS}

\section{Selection of clinical tests}

The clinical tests outlined in the Southampton schedule formed the basis of the examination series used in the study. ${ }^{10}$ Additional tests commonly used for assessment of the rotator cuff were included (table 1). The assessors consisted of a consultant rheumatologist with a particular interest in shoulder disorders, a specialist registrar in rheumatology without specific training in shoulder complaints, and a research nurse with no formal musculoskeletal training. The assessment of the consultant was deemed the benchmark against which other assessments were compared.

\section{Sample population}

The study group consisted of consecutive patients with shoulder pain referred to the rheumatology unit at a teaching hospital, as well as patients identified in the rheumatology outpatients department whose chief complaint was shoulder pain. The patients were then assessed in a second weekly clinic held at the hospital. Inclusion criteria for participation in the study included ability to give informed consent; age 20-85 years; and shoulder pain regardless of possible 
Table 1 Tests used in shoulder examination

\begin{tabular}{|c|c|c|}
\hline Test & Description & Algorithm for diagnosis \\
\hline Empty can test for supraspinatus & $\begin{array}{l}\text { The shoulder is abducted to } 90^{\circ} \text { then internally rotated and brought into } 30^{\circ} \\
\text { forward flexion by the examiner, with thumb pointing downwards. The } \\
\text { patient abducts the arm against the examiner's resistance }\end{array}$ & $\begin{array}{l}\text { Pain indicates tendinitis/tendinosis } \\
\text { Weakness out of proportion to pain } \\
\text { indicates tear }\end{array}$ \\
\hline $\begin{array}{l}\text { Resisted external rotation for } \\
\text { infraspinatus }\end{array}$ & $\begin{array}{l}\text { External rotation resisted with the patient's arm at the side, externally rotated } \\
20^{\circ} \text { and the elbow flexed to } 90^{\circ}\end{array}$ & $\begin{array}{l}\text { Pain indicates tendinitis/tendinosis } \\
\text { Weakness out of proportion to pain } \\
\text { indicates tear }\end{array}$ \\
\hline Lift off test for subscapularis & $\begin{array}{l}\text { The dorsal aspect of the hand is placed on the ipsilateral buttock and the } \\
\text { hand is then lifted off the buttock } 1-2 \text {. The hand is then lifted further against } \\
\text { the resistance applied by the examiner }\end{array}$ & $\begin{array}{l}\text { Pain indicates tendinitis/tendinosis } \\
\text { Weakness out of proportion to pain } \\
\text { indicates tear }\end{array}$ \\
\hline Yergason's test & $\begin{array}{l}\text { With the arm by the side and the forearm flexed to } 90^{\circ} \text { the forearm is } \\
\text { supinated against resistance }\end{array}$ & $\begin{array}{l}\text { Positive test: pain in region of bicipital } \\
\text { groove indicates tendinitis }\end{array}$ \\
\hline Speeds test & $\begin{array}{l}\text { With the elbow fully extended and the arm in } 30^{\circ} \text { of flexion further flexion is } \\
\text { resisted by the examiner }\end{array}$ & $\begin{array}{l}\text { Positive test: pain in region of bicipital } \\
\text { groove indicates tendinitis }\end{array}$ \\
\hline $\begin{array}{l}\text { Hawkins-Kennedy impingement } \\
\text { test }\end{array}$ & $\begin{array}{l}\text { With the patient standing the arm is abducted to } 90^{\circ} \text { and forward flexed to } \\
45^{\circ} \text {. The arm is then forcibly internally rotated }\end{array}$ & Positive test elicits pain \\
\hline Acromioclavicular joint assessment & $\begin{array}{l}\text { With patient seated the examiner passively adducts the arm at } 90^{\circ} \text { abduction } \\
\text { across the chest } \\
\text { Alternative test: with the patient standing the examiner passively adducts the } \\
\text { extended arm in front of the body }\end{array}$ & $\begin{array}{l}\text { Pain at } A C \text { joint indicates pathology } \\
\text { (sprain or OA) } \\
\text { Pain at } A C \text { joint indicates pathology } \\
\text { (sprain or OA) }\end{array}$ \\
\hline $\begin{array}{l}\text { Drop arm test for rotator cuff } \\
\text { rupture }\end{array}$ & $\begin{array}{l}\text { The examiner passively abducts the arm to } 90^{\circ} \text { with subsequent active } \\
\text { adduction }\end{array}$ & $\begin{array}{l}\text { Positive test: subject is unable to } \\
\text { maintain abduction. Indicates rotator } \\
\text { cuff rupture }\end{array}$ \\
\hline
\end{tabular}

underlying aetiology. All patients who were referred were offered appointments; however, a small number cancelled before review as their symptoms had improved. Patient characteristics of this group are unknown.

\section{Training}

Before starting the trial, two consultant-led training sessions for the other assessors occurred over consecutive weeks. Ten patients were examined by a method similar to that described by Palmer et al..$^{10}$ The sessions aimed at ensuring that the observing assessors were familiar with the clinical tests involved in the examination series and how to perform them. A handbook, with full details of all clinical tests as they have been reported, was given to each observer. "Training patients" comprised predominantly those with rotator cuff tendinopathy as formally diagnosed by the consultant. Each observer examined the patient under the supervision of the trainer.

\section{Shoulder assessment}

The assessment involved three phases, starting with historical information obtained by the first observer. This was

Table 2 Baseline characteristics of study subjects

\begin{tabular}{ll}
\hline Characteristics & \\
\hline Total subjects (n) & 136 \\
Men, No (\%) & $66(49)$ \\
Women, No (\%) & $70(51)$ \\
Age (years), mean (range) & 55 \\
Total & $53(20-70)$ \\
Men & $58(20-85)$ \\
Women & 159 \\
Affected shoulders (n) & 64 \\
Total & 49 \\
Right only & 23 \\
Left only & 113 \\
Both left and right & \\
Unaffected shoulders & 123 \\
Dominant arm (n) & 12 \\
Right & 1 \\
Left & \\
Both & $22.9(1-144)$ \\
Duration of symptoms (months) & 12 \\
Mean (range) & \\
Median &
\end{tabular}

followed by inspection of the shoulder for signs of swelling, deformity, tenderness, winging, degree of external rotation, and a "painful arc". Finally, assessment of each part of the rotator cuff was undertaken by resistance testing and was defined as either normal, weakness $>$ pain (implying tear), or pain $>$ weakness (implying tendinosis/tendinitis). ${ }^{19}$ Other tests involved assessment of the long head of biceps (Speed and Yerguson tests ${ }^{12}$ ), signs of impingement using the Hawkins-Kennedy test, and assessment of the acromioclavicular joint (table 1). A provisional diagnosis was made using a predefined algorithm, depending upon the history and examination findings. More than one final diagnosis was possible using this algorithm (table 1).

\section{Statistical methods}

Between-observer reproducibility of physical signs of shoulder disease was evaluated using Cohen's $\kappa$ coefficient for categorical variables. ${ }^{24}$ Cohen's $\kappa$ is the preferred statistic for the evaluation of concordance between two clinicians for nominal categories measuring agreement beyond that expected to occur by chance. Landis and Koch proposed guidelines for the interpretation of the strength of concordance reflected by the $\kappa$ coefficient: $<0.00$ "poor"; 0.00-0.20 "slight"; 0.21-0.40 "fair"; 0.41-0.60 "moderate"; 0.61-0.80 "substantial"; 0.81-1.00 "almost perfect". ${ }^{25}$ A minimum sample size of 125 was chosen on the basis that an observed $\kappa$ coefficient for a test would then have a $95 \%$ confidence interval that covered at most one of these concordance categories either side of the coefficient, on the assumption that the tests would have a test prevalence lying between 20 and $80 \%$.

It is accepted that the sample size will not allow reproducibility of tests for the rare lesions-for example, subscapularis tendinopathies, to be evaluated with precision. Systematic bias between observers was examined with McNemar's test. We did not evaluate intraobserver agreement.

\section{RESULTS}

In total, 136 patients were enrolled in the study over a 12 month period. Table 2 shows their demographic information. The number of affected shoulders was 159 with 23 subjects contributing two sets of observations for assessment; 113 shoulders were normal. The analysis assumes independent observations; however, the patients who contributed 
Table 3 Agreement between the three clinicians about the presence of tenderness, painful arc, and external rotation in affected shoulders

\begin{tabular}{|c|c|c|c|c|c|c|}
\hline \multirow[b]{2}{*}{ Observations } & \multicolumn{3}{|c|}{ Prevalence $(\%) \dagger$} & \multicolumn{3}{|l|}{ к Value } \\
\hline & Consultant & Spec reg & Nurse & Cons/spec reg & Cons/nurse & Spec reg/nurse \\
\hline $\begin{array}{l}\text { Tenderness } \\
\text { Painful arc } 1 \text { (start of pain) } \\
\text { Painful arc } 2 \text { (end of pain) } \\
\text { External rotation }\left(<45^{\circ}\right)\end{array}$ & $\begin{array}{l}68(n=159) \\
82(n=159) \\
83(n=159) \\
25(n=158)\end{array}$ & $\begin{array}{l}55(n=159) \\
88(n=159) \\
89(n=159) \\
28(n=159)\end{array}$ & $\begin{array}{l}58(n=159) \\
85(n=159) \\
86(n=159) \\
45(n=158)\end{array}$ & $\begin{array}{l}0.32^{* *} \ddagger \\
0.48^{* *} \ddagger \\
0.64^{* *} \ddagger \\
0.68^{* *}\end{array}$ & $\begin{array}{l}0.26^{* *} \\
0.50^{* *} \\
0.61^{* *} \\
0.42^{* *} \ddagger\end{array}$ & $\begin{array}{l}0.48^{* *} \\
0.49^{* *} \\
0.62^{* *} \\
0.46^{* *} \ddagger\end{array}$ \\
\hline
\end{tabular}

both shoulders represent a relatively small percentage of subjects and are unlikely to have an effect on the results.

$\kappa$ Coefficients were calculated for all phases of the assessment. All tests were scored on a dichotomous scale. Fair to substantial agreement was obtained for the observations of tenderness, painful arc, and for external rotation (table 3). Agreement between raters was reduced owing to the lower level of prevalence of tenderness rated by the specialist registrar and nurse and the higher level of prevalence of external rotation rated by the nurse.

Tests for supraspinatus and subscapularis also showed at least fair agreement between observers (table 4). Tests for the acromioclavicular joint showed the poorest reproducibility (table 4). Adequate rater agreement in these tests for the overall prevalence among the three raters and agreement in an individual patient was not achievable.

According to the algorithm, diagnosis of shoulder pain showed at least fair concordance for rotator cuff disorders, adhesive capsulitis, and for referred pain, and this was largely associated with a tendency for overestimation of the prevalence of diagnoses by the nurse and specialist registrar relative to consultant. The diagnosis of impingement and acromioclavicular joint disease between consultant and nurse showed only slight agreement (table 5) (fig 1). When the patients were stratified by age, duration of symptoms, sex, and night pain, no improvement in reproducibility for a diagnosis of impingement was found (table 6). In total 40/55 $(73 \%)$ of the $\kappa$ coefficient assessments were rated at $>0.2$, indicating at least fair concordance between observers; 21/55 $(38 \%)$ were rated at $>0.40$, indicating at least moderate concordance between observers. There was almost total agreement between observers in assessment of the unaffected shoulder. More detailed analysis of the agreement between observers with full $2 \times 2$ tables is available (see Appendix 1 at http://www.annrheumdis.com/supplemental).

\section{DISCUSSION}

The results of our study show slight to substantial agreement among observers of varying experience in assessment of the rotator cuff in patients attending a hospital clinic. This is comparable with most previous studies looking at interobserver agreement of shoulder disorders, although the correlation between research nurse, registrar, and consultant, to our knowledge, has not previously been studied. In addition, earlier studies were not designed to look specifically at the rotator cuff, which represents a narrower field. The results suggest that, with training, delegation of assessment of the shoulder to health staff with no particular expertise may be possible as the optimal agreement for diagnosis was between the specialist registrar and research nurse. This could be useful for epidemiological studies as well as for triage purposes in primary care to maximise use of resources. ${ }^{11}$

In a study by de Winter et al, reproducibility was moderate $(\kappa=0.45)$ between two physiotherapists assessing shoulder disorders. ${ }^{26}$ The poorest diagnostic agreement was found for subjects with a high degree of pain, bilateral involvement, and chronic complaints. Their patient population was more selective than in our study and therefore our results might have improved if we had not included patients with shoulder pain regardless of possible underlying cause. One explanation for the diagnostic disagreement in the study of de Winter et al was the insufficient mutual exclusivity of diagnostic categories currently used for shoulder disorders-an example being pain associated with adhesive capsulitis rendering any further assessment of the shoulder difficult. In the study of Liesdek et al, ${ }^{20}$ in contradistinction to that of de Winter et al, ${ }^{26}$ agreement between general practitioners and physiotherapists in diagnosis of soft tissue disorders of the shoulder was greater in patients with a long duration of symptoms. Their overall $\kappa$ value for the classification of shoulder disorders was fair at 0.31 and might have been an overestimation, as the physiotherapists were not "blinded" to the diagnosis of the general practitioners.

Bamji et al showed poor agreement between consultant rheumatologists in shoulder assessment, with agreement in only $46 \%$ when examined independently and $78 \%$ when assessed together. ${ }^{21}$ One study has, however, shown very high agreement between physiotherapists, ${ }^{22}$ which is in contrast

Table 4 Agreement between three clinicians about resistance testing in the affected shoulder

\begin{tabular}{|c|c|c|c|c|c|c|}
\hline \multirow[b]{2}{*}{ Tests } & \multicolumn{3}{|l|}{ Prevalence $(\%) \dagger$} & \multicolumn{3}{|l|}{ к Value } \\
\hline & Consultant & Spec reg & Nurse & Cons/spec reg & Cons/nurse & Spec reg/nurse \\
\hline Supraspinatus (empty can test) & $68(n=157)$ & $79(n=158)$ & $75(n=158)$ & $0.49^{* *} \ddagger$ & $0.44^{* *}$ & $0.46^{* *}$ \\
\hline Infraspinatus (resisted external rotation) & $44(n=156)$ & $47(n=158)$ & $52(n=159)$ & $0.45^{\star *}$ & $0.18^{*}$ & $0.38^{* *}$ \\
\hline Subscapularis (lift off test) & $44(n=156)$ & $54(n=158)$ & $55(n=159)$ & $0.30^{* *}$ & $0.32^{* *} \ddagger$ & $0.28^{* *}$ \\
\hline Long head of biceps (Yergason's test) & $0(n=158)$ & $9(n=157)$ & $16(n=157)$ & N/A $₫$ & $\mathrm{~N} / \mathrm{A} \pm \S$ & $0.276^{* *} \ddagger$ \\
\hline Long head of biceps (Speeds test) & $13(n=158)$ & $25(n=159)$ & $30(n=159)$ & $0.17^{*} \ddagger$ & $0.26^{* *} \ddagger$ & $0.32^{\star *}$ \\
\hline Impingement (Hawkins-Kennedy) & $49(n=152)$ & $73(n=158)$ & $68(n=156)$ & $0.29^{* *} \ddagger$ & $0.18^{*} \ddagger$ & $0.43^{* *}$ \\
\hline Acromioclavicular joint (elevation) & $14(n=134)$ & $30(n=148)$ & $50(n=149)$ & $0.19^{*} \ddagger$ & $0.20^{* *} \ddagger$ & $0.30^{* *} \ddagger$ \\
\hline Acromioclavicular joint (adduction front) & $7(n=141)$ & $26(n=152)$ & $42(n=158)$ & $0.09 \ddagger$ & $0.08 \ddagger$ & $0.29^{* *} \ddagger$ \\
\hline Acromioclavicular joint (adduction back) & $1(n=138)$ & $25(n=147)$ & $52(n=142)$ & $0.06 \ddagger$ & $0.03 \ddagger$ & $0.38^{* *} \ddagger$ \\
\hline Drop arm test & $0.8(n=126)$ & $4(n=129)$ & $2(n=135)$ & $0.275^{\star *}$ & $0.659^{* *}$ & $0.528^{* *}$ \\
\hline
\end{tabular}

${ }^{*} p<0.05,{ }^{* *} p<0.01$; tprevalence is the percentage of affected shoulders which were found to test positive; $\ddagger$ McNemar $p<0.05$ denoting significant difference in prevalence between the two raters; §not applicable owing to a prevalence of zero. 


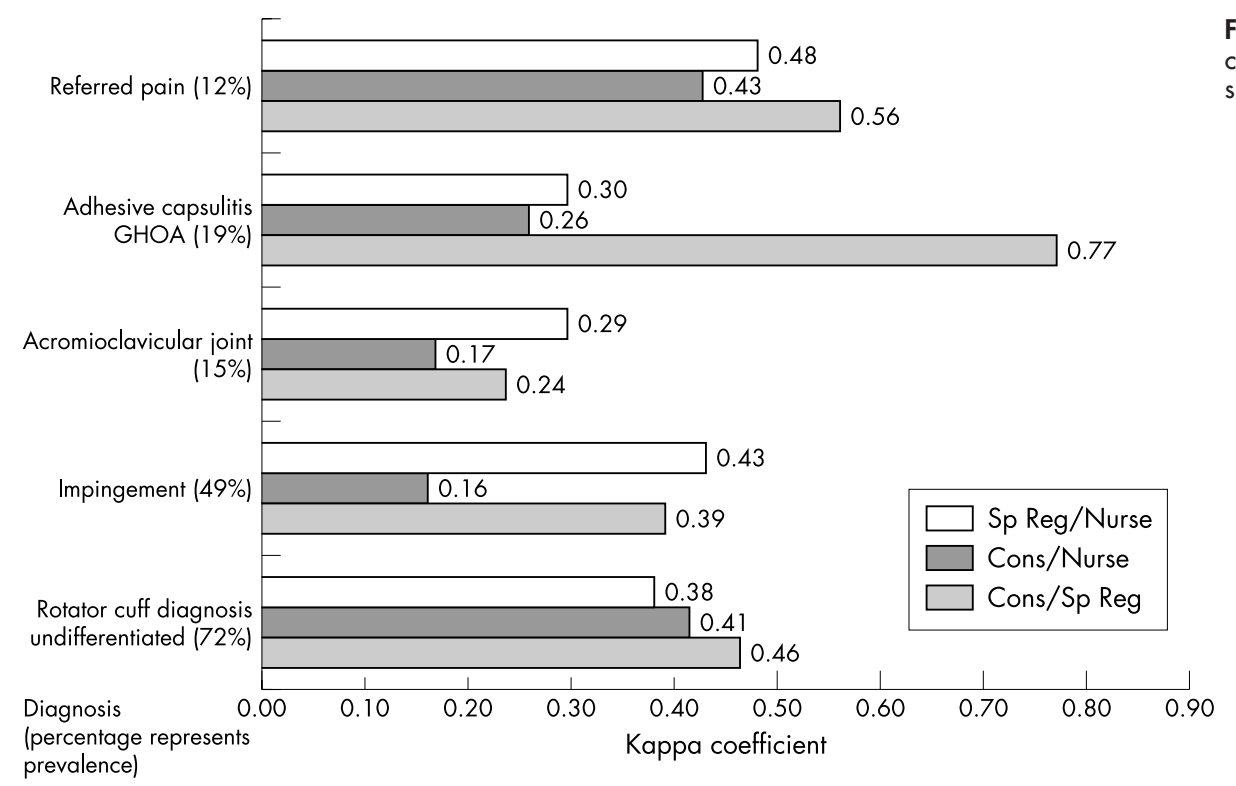

Figure 1 Agreement among three clinicians in diagnosis in affected shoulders assessed by $\kappa$ coefficient.

with the other interobserver studies. The limitations of this study were the small numbers (19 patients), the paucity of information on the clinical characteristics of the patients, and the setting of the study.

The difficulty in assessing soft tissue disorders of the shoulder is further highlighted by observer variability in shoulder movement. Croft et al found that the assessment of external rotation was poorly reproducible owing to random variation in visual estimation and systematic variation in examination technique. ${ }^{27}$ In a study by Hoving et al, adequate reliability was only obtained for the movements of total shoulder flexion and hand behind back. ${ }^{28}$

Our results show that there was at least moderate agreement for lesions of the supraspinatus muscle and for signs of capsulitis. A limitation of the $\kappa$ value, when the background prevalence of the parameter in question is particularly low or high, is that $\kappa$ coefficients have been shown to be smaller than when the prevalence is in the middle of the range $(50 \%)$ when the sensitivity and specificity of the test are kept the same. Another limitation with extreme prevalence is that the $\kappa$ coefficient has relatively large sample to sample variability and wide confidence intervals. Taken together, these limitations may partially explain the reduced reproducibility in tests for less common lesions, which would require evaluation in a larger sample. Differences in prevalence between study populations also complicate effective comparison of $\kappa$ coefficients between studies because the observed value of $\kappa$ depends on the similarity of prevalence in the studies. ${ }^{29}$

It is axiomatic that the true worthiness of a diagnostic test lies in its ability to alter treatment and/or in prognostication.
There is unfortunately scant evidence about the usefulness of clinical tests for shoulder disease in either of these areas. As the reproducibility of many of the tests in our study was poor, this hampers further efforts to use a large set of tests by various practitioners to aid in shoulder pain management. This issue is further complicated when assessment is undertaken in general practice, where the presentation or severity of disease may be quite different from that seen in a teaching hospital. The minimum set of tests we found to have at least moderate reproducibility comprised those for painful arc, external rotation, and empty can. This is a reasonable start as these tests imply lesions of the capsule (such as frozen shoulder, which is notoriously recalcitrant to treatment) and supraspinatus, the most commonly affected muscle in rotator cuff lesions and hence the main culprit causing shoulder pain.

Although we focused principally on rotator cuff lesions, rarer diagnoses encountered, such as instability, reflex sympathetic dystrophy, myofascial pain, and fibromyalgia, were not included in the diagnostic algorithm. The research nurse, who had no previous knowledge of shoulder disorders, could not make these diagnoses. This highlights one the limitations of this study and the difficulties in standardising the examination. Missing rare diagnoses by less experienced staff may not be important, however, as patients with an unclear initial assessment could be referred for specialist opinion. We felt a diagnostic algorithm was necessary in order to translate the clinical signs into an entity which could be used for treatment.

The usual management of rotator cuff lesions, although not adequately validated $^{8}$ but employed by clinicians,

Table 5 Agreement between the three clinicians about diagnosis of affected arm

\begin{tabular}{|c|c|c|c|c|c|c|}
\hline \multirow[b]{2}{*}{ Diagnosis } & \multicolumn{3}{|c|}{ Prevalence $(\%) \dagger$} & \multicolumn{3}{|l|}{ к Value } \\
\hline & Consultant & Spec reg & Nurse & Cons/spec reg & Cons/nurse & Spec reg/nurse \\
\hline $\begin{array}{l}\text { Rotator cuff diagnosis (undifferentiated) } \\
\text { Impingement } \\
\text { Acromioclavicular joint } \\
\text { Adhesive capsulitis/GHOA } \\
\text { Referred pain }\end{array}$ & $\begin{array}{l}72(n=153) \\
49(n=156) \\
15(n=156) \\
19(n=156) \\
12(n=156)\end{array}$ & $\begin{array}{r}82(n=158) \\
69(n=159) \\
27(n=159) \\
23(n=159) \\
7(n=159)\end{array}$ & $\begin{array}{l}82(n=159) \\
66(n=159) \\
46(n=159) \\
33(n=159) \\
14(n=159)\end{array}$ & $\begin{array}{l}0.46^{* *} \ddagger \\
0.39^{* *} \ddagger \\
0.24^{* *} \ddagger \\
0.77^{* *} \\
0.56^{* *} \ddagger\end{array}$ & $\begin{array}{l}0.41^{* *} \ddagger \\
0.16^{*} \ddagger \\
0.17^{* *} \ddagger \\
0.26^{* *} \ddagger \\
0.43^{* *}\end{array}$ & $\begin{array}{l}0.38^{* *} \\
0.43^{* *} \\
0.29^{* *} \ddagger \\
0.30^{* *} \ddagger \\
0.30^{* *} \ddagger\end{array}$ \\
\hline
\end{tabular}

${ }^{*} p<0.05,{ }^{* *} p<0.01$; tprevalence is the percentage of affected shoulders which were found to test positive; $¥ M c N e m a r p<0.05$ denoting significant difference in prevalence between the two raters. 
Table 6 Agreement between clinicians about assessment of impingement related to age, sex, duration of symptoms, and presence of night pain

\begin{tabular}{lllll}
\hline Diagnosis of impingement & $\begin{array}{l}\text { Consultant/ } \\
\text { Spec reg }\end{array}$ & $\begin{array}{l}\text { Consultant/ } \\
\text { Nurse }\end{array}$ & $\begin{array}{l}\text { Spec reg/ } \\
\text { Nurse }\end{array}$ & Total \\
\hline Age $<55$ years & 0.40 & 0.26 & 0.45 & 70 \\
Age $\geqslant 55$ years & 0.19 & 0.1 & 0.34 & 81 \\
Duration $\leqslant 12$ weeks & 0.13 & 0.15 & $0.37^{* *}$ & 83 \\
Duration $>12$ weeks & $0.53^{* *}$ & 0.23 & $0.49^{* *}$ & 68 \\
In men & $0.28^{* *}$ & $0.23^{* *}$ & $0.57^{* *}$ & 75 \\
In women & $0.32^{* *}$ & 0.13 & $0.30^{* *}$ & 76 \\
With night pain & $0.30^{* *}$ & $0.16^{* *}$ & $0.38^{* *}$ & 138 \\
With no night pain & 0.24 & 0.40 & $0.84^{* *}$ & 13 \\
\hline${ }^{*} p<0.05,{ }^{* *} p<0.01$ & & & & \\
\hline
\end{tabular}

involves a variable combination of analgesics, physiotherapy, and injection of corticosteroid and local anaesthetic into the subacromial space or glenohumoral joint. This may be initiated in primary care, with referral of the more severe or unclear cases to specialist clinics. Patients who undergo this treatment paradigm who do not improve could also be referred for specialist assessment.

Despite an attempt at standardisation made in the Southampton Examination Schedule, diagnosis of rotator cuff pathology was the most difficult and the least defined. Training of the observers lasted for 6 weeks until consistency was optimised, compared with two teaching sessions in our study, making it less applicable to daily practice. Our results will have to be repeated, however, to see if the reproducibility holds across all practitioners who deal with shoulder disorders and in primary care where subjects may have less defined illness. Our results might have improved with a longer duration and more intensive training session.

Validation of specific clinical tests requires a standard of reference which in many cases may not be available or easily accessible. In our study the consultant's opinion was taken as the benchmark, as has been used in other studies ${ }^{10}$; however, this has limitations as true validity is not assessed. The consultant's opinion was deemed appropriate and adequate, however, for a reproducibility study of this nature.

Primary care is the most appropriate location for appraisal of shoulder disorders. Direct orthopaedic referral in many institutions is becoming increasingly difficult, with the implication of increased referral to the rheumatology department. If most shoulder disorders could be adequately managed in primary care this would significantly reduce the tertiary referral workload.

In summary, this study has identified the reproducibility of certain tests, employed by observers of varying experience, in the assessment of the rotator cuff and general shoulder disease. Further study of these tests is required across all disciplines involved with shoulder disease. The results have important implications for future epidemiological and treatment studies.

\section{ACKNOWLEDGEMENTS}

Consulting services at the Centre for Applied Medical Statistics, University of Cambridge provided statistical support.

\section{Authors' affiliations}

A J K Ostor, C A Richards, A T Prevost, B L Hazleman, C A Speed,

Rheumatology Research Unit, Addenbrooke's Hospital, Cambridge, UK

\section{REFERENCES}

1 Croft PR, Pope DP, Silman A. The clinical course of shoulder pain:prospective cohort study in primary care. BMJ 1996;313:601-2.

2 van der Windt DA, Koes BW, Boeke AJ, Deville W, De Jong BA, Bounter LM. Shoulder disorders in primary care: prognostic indicators of outcome. $\mathrm{Br} J \mathrm{Gen}$ Pract 1996;46:519-23.

3 Macfarlane GJ, Hunt IM, Silman AJ. Predictors of chronic shoulder pain: a population based prospective study. J Rheumatol 1998;25:1612-15.
4 Royal College of General Practitioners. Office of Population Census and Surveys, Department of Health and Social Security. Morbidity statistics from general practice. Third national study:socio-economic analyses. London: HMSO, 1986 (Series MB5 No 2)

5 Bjelle A. Epidemiology of shoulder problems. Baillieres Clin Rheumatol 1989:3:437-51.

6 Chard MD, Hazleman R, Hazleman BL, King RH, Reiss BB. Shoulder disorders in the elderly: a community survey. Arthritis Rheum 1991;34:766-9.

7 Buchbinder R, Goel V, Bombardier C, Hogg-Johnson S. Classification systems of soft tissue disorders of the neck and upper limb: do they satisfy methological guidelines? J Clin Epidemiol 1996;49:141-9.

8 Green S, Buchbinder R, Glazier R, Forbes A. Interventions for shoulder pain (Cochrane review). In: The Cochrane Library. Oxford: Update Software, 2002;(3).

9 Harrington JM, Carter JT, Birrell L, Gompertz D. Surveillance case definitions for work related upper limb pain syndromes. Occup Environ Med 1998;55:264-71.

10 Palmer K, Walker-Bone K, Linaker C, Reading I, Kellingray S, Coggon D, et al. The Southampton examination schedule for the diagnosis of musculoskeletal disorders of the upper limb. Ann Rheum Dis 2000;59:5-11.

11 Walker-Bone K, Byng P, Linaker C, Reading I, Coggon D, Palmer K, et al. Reliability of the Southampton examination schedule for the diagnosis of upper limb disorders in the general population. Ann Rheum Dis 2002;61:1103-6.

12 Magee DJ. Shoulder. In: Orthopaedic physical assessment. 2nd ed. Philadelphia: Saunders 90-142.

13 Pope DP, Croft PR, Pritchard CM, Silman AJ. Prevalence of shoulder pain in the community: the influence of case definition. Ann Rheum Dis 1997:56:308-12.

14 Balich SM, Sheley RC, Brown TR, Sauser DD, Quinn SF. MR imaging of the rotator cuff tendon: interobserver agreement and analysis of interpretative errors. Radiology 1997;204:191-4

15 Neer CS. Impingement lesions. Clin Orthop 1983;173:70-7.

16 Uhthoff HK, Sarkar K. An algorithm for shoulder pain caused by soft-tissue disorders. Clin Orthop 1990;254:121-7.

17 Hedtmann A, Fett H. The so-called periarthropathic humeroscapularis. Classification and analysis of 1266 cases. Z Orthop 1989;127:643-9.

18 Bakker JF, de Jongh L, Jonquière M, Mens J, Oosterhun WW, Poppelaars A, et al. Standaard Schouderklachten. Huisarts en Wetenschap 1990;33:196-202.

19 Cyriax J. Textbook of orthopaedic medicine, 7th ed. London: Baillière Tindall, 1981:190-239.

20 Liesdek C, van der Windt DAWM, Koes BW, Bouter LM. Soft-tissue disorders of the shoulder: a study of inter-observer agreement between general practitioners and physiotherapists and an overview of physiotherapeutic treatment. Physiotherapy 1997;83:12-17.

21 Bamii AN, Erhardt CC, Price TR, Williams PL. The painful shoulder: can consultants agree? Br J Rheumatol 1996:35:1172-4.

22 Pellecchia GL, Paolino J, Connell J. Intertester reliability of the Cyriax evaluation in assessing patients with shoulder pain. J Orthop Sports Phys Ther 1996;23:34-8.

23 Nørregaard J, Krogsgaard MR, Lorenzen T, Jensen EM. Diagnosing patients with longstanding shoulder joint pain. Ann Rheum Dis 2002;61:646-9.

24 Cohen J. A coefficient of agreement for nominal scales. Educ Psychol Measure 1960;20:37-46.

25 Landis JR, Koch GG. The measurement of observer agreement for categorical data. Biometrics 1977;33:159-74.

26 de Winter AF, Jans MP, Scholten RJPM, Devillé W, van Schaardenburg D, Bounter LM. Diagnostic classification of shoulder disorders: interobserver agreement and determinants of disagreement. Ann Rheum Dis 1999:58:272-7.

27 Croft P, Pope D, Boswell R, Rigby A, Silman A. Observer variability in measuring elevation and external rotation of the shoulder. $\mathrm{Br} J$ Rheumatol 1994;33:942-6.

28 Hoving JL, Buchbinder R, Green S, Forbes A, Bellamy N, Brand C, et al. How reliably do rheumatologists measure shoulder movement? Ann Rheum Dis 2002;61:612-16

29 Thompson WD, Walter SD. A reappraisal of the kappa coefficient. J Clin Epidemiol 1988;41:949-58. 